\title{
On the evaluation of interface quality in concrete repair system by means of impact-echo signal analysis
}

\author{
Andrzej Garbacz ${ }^{\mathrm{a}, *}$, Tomasz Piotrowski ${ }^{\mathrm{a}}$, Luc Courard ${ }^{\mathrm{b}}$, Lesław Kwaśniewski ${ }^{\mathrm{c}}$ \\ ${ }^{a}$ Warsaw University of Technology, Faculty of Civil Engineering, Department of Building Materials Engineering, Al. Armii Ludowej 16, PL 00637 Warsaw, Poland \\ ${ }^{\mathrm{b}}$ University of Liège, Faculty of Applied Sciences, ArGEnCO Department, Allée de la découverte, 9, 4000 Liège, Belgium \\ ${ }^{c}$ Warsaw University of Technology, Faculty of Civil Engineering, Department of Theoretical Mechanics and Pavement Modelling, Al. Armii Ludowej 16, PL 00637 Warsaw, Poland
}

\section{H I G H L I G H T S}

- Concrete substrate roughness and microcracking influence stress wave propagation.

- No relation between bond strength and amplitudes of frequency peaks in IE spectrum.

- Proposed FE model is useful for simulation of stress wave propagation in repair systems with different interface quality.

- Bond strength estimation with IE needs advanced signal analysis e.g. wavelet analysis.

\section{A R T I C L E I N F O}

Article history:

Received 19 May 2016

Received in revised form 11 December 2016

Accepted 16 December 2016

\section{Keywords:}

Concrete repair

Adhesion

Concrete substrate quality

Nondestructive testing

Frequency spectrum

Wavelet analysis

\begin{abstract}
A B S T R A C T
According to Concrete Repair Manual as well as ACI 562-16 and European EN 1504-10 standards, a bond strength as a measure of adhesion is one the main feature of repair system necessary to be assessed. The most common laboratory and engineering method for bond strength evaluation is pull-off test. This is however a semi-destructive method that needs a repair in a place of measurement. Recently, the great interest in nondestructive techniques (NDT) development is noted. Impact-echo (IE) is considered as one of the most promising methods for this purpose.

In this paper, the study on the usability the IE test based on frequency spectrum analysis for bond strength evaluation is analyzed. Both Finite Element Method (FEM) simulation and experimental tests were performed in order to obtain potential relations between IE frequency spectrum and parameters characterizing concrete substrate quality that may affect the final bond strength and the real value of pull-off bond strength measured on samples as well. It was concluded that the IE method can be a useful tool for interface quality and bond strength evaluations in concrete repair system. However, more complex signal analysis, e.g. wavelet analysis, should be considered in the future.
\end{abstract}

(c) 2016 Elsevier Ltd. All rights reserved.

\section{Introduction}

In concrete repair systems a specific interface is created. Its quality is affecting the adhesion and as a consequence reliability and durability of repair [1-3]. Adhesion is understood as a process through which two bodies are brought together and attached bonded - to each other: it has therefore two different aspects, according to whether interest is mainly either in the conditions and the kinetics of contact or in the separation process [4]. An interface with good adhesion between concrete substrate and repair material is usually treated as a high quality interface. Many factors are influencing adhesion. The most important ones are con-

\footnotetext{
* Corresponding author.

E-mail address: a.garbacz@il.pw.edu.pl (A. Garbacz).
}

crete substrate characteristic (e.g. laitance, roughness, surface saturation, microcracking level etc.), repair material properties and application technology [5]. The bond strength is considered as a technical measure of adhesion and can be measured with different methods. EN 1504 [6] in general recommendations over quality control/quality assessment (QC/QA) suggests the pull-off test [7] for evaluation of adhesion of repair materials as relevant. It is commonly used in laboratory and onsite for evaluation of bond strength [6,8-9]. However this kind of test is usually insufficient for interface quality evaluation in large area concrete repair. The NDT methods could be very useful in such case. They allow the monitoring of the object after repair as well [10]. Impact-echo (IE) method is considered as the most promising one because it is less sensitive to heterogeneity of concrete in comparison to e.g. ultrasonic [11]. In the IE method a low energy impact of a steel 
ball on the surface is used to generate stress waves that propagate through the structure and are reflected by interfaces within the material or external boundaries (Fig. 1a). Additional feature of IE method besides a time-domain analysis (Fig. 1b) is frequency spectrum analysis (Fig. 1c).

IE method is often used for quality control of various types of repair, e.g. injection of cable ducts, overlays etc. Usually, defects like voids or delamination are detected. Lin et al. [12] observed some differences in frequency spectrums for two overlay systems with different bond strength (Fig. 2). However, they concluded that those differences were not significant for evaluation of bond strength. The aim of this paper is to study the usability of the IE test based on frequency spectrum analysis for evaluation of bond strength in repair systems.

\section{Concrete substrate quality and bond strength of tested repair systems}

A surface preparation of concrete substrate is the basic operation before a repair system application. It has been widely demonstrated that it can significantly influence on the microcracking level and surface roughness, substrate saturation level and as a consequence it may affect the bond strength between repair material and concrete substrate [3,13-18]. The effect of surface quality on impact-echo signal was investigated for two groups of concrete substrates (Table 1). Effect of near-to-surface properties on bond strength for those groups was discussed in previous paper by Courard et al. [19].

The surface quality was described by means of following parameters: Surface Roughness Index (SRI) defined in EN 1766, microcracking density $\left(L_{A}\right)$ (Fig. 3) [19] and surface tensile strength $\left(f_{h s}\right)$ defined in EN 1504-10 and measured according to EN 1542 (Fig. 4), resulting from different surface preparation techniques. In [19] it was concluded that surface tensile strength is an accurate parameter characterizing the quality of substrate prior to repair and is easier to evaluate than density of microcracks.

On the base of the results of pull-off bond strength (Fig. 5) for different qualities of concrete, it is clear that compressive strength of concrete is not a discriminate important parameter for evaluation of adhesion in repair systems but selection of surface treatment technique should be preceded by the analysis of its aggressiveness in relation to the concrete substrate strength, taking into account both the development of the roughness profile and the decrease of surface tensile strength due to microcracks in the near-to-surface layer.

\section{Impact-echo measurement and signal analysis}

Impact-echo (IE) is a method used for non-destructive evaluation of concrete: it is based on the use of elastic, low energy impact
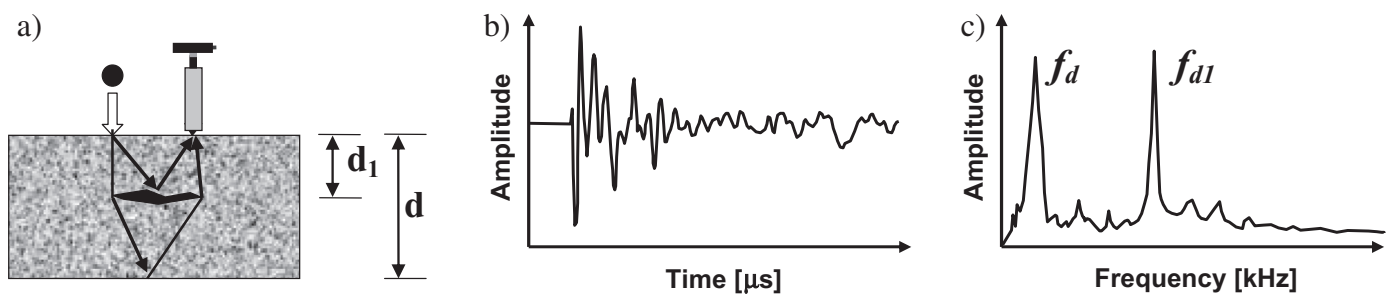

Fig. 1. Scheme of impact-echo method (a), example of waveform (b) time-domain spectrum and (c) corresponding frequency when defect in concrete is observed.
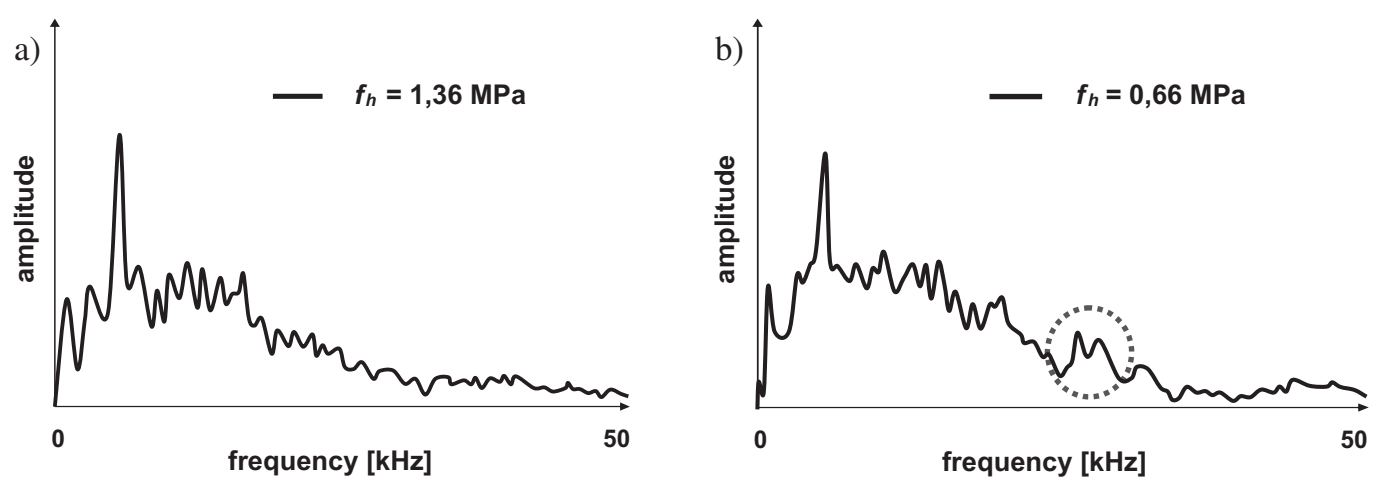

Fig. 2. Frequency spectrums for overlay systems with different bond strengths, $f_{h}$ tested in lab conditions (acc.[12]).

Table 1

Characteristic of tested repair systems.

\begin{tabular}{|c|c|c|c|c|c|c|}
\hline \multirow[b]{2}{*}{ Concrete substrate } & \multicolumn{3}{|l|}{ Group A } & \multicolumn{3}{|l|}{ Group B } \\
\hline & $\mathrm{C} 30$ & $\mathrm{C} 40$ & $\mathrm{C} 45$ & $\mathrm{C} 25$ & C35 & C50 \\
\hline Compressive strength classes & $\mathrm{C} 30 / 37$ & $\mathrm{C} 40 / 50$ & $\mathrm{C} 45 / 55$ & $\mathrm{C} 25 / 30$ & C35/45 & C50/60 \\
\hline Surface preparation & \multicolumn{3}{|c|}{$\begin{array}{l}\mathrm{PL} \text { - polishing, SB-D - dry sandblasting, JH - jack } \\
\text { hammering, HD - hydrodemolition }\end{array}$} & \multicolumn{3}{|c|}{$\begin{array}{l}\text { BR - brusing, SB-W - wet sandblasting, SC - } \\
\text { scarifing, LC - water cleaning }\end{array}$} \\
\hline Substrate sample dimensions & \multicolumn{3}{|c|}{$80 \times 60 \times 10 \mathrm{~cm}$} & \multicolumn{3}{|c|}{$50 \times 50 \times 7 \mathrm{~cm}$} \\
\hline Repair material & \multirow{2}{*}{\multicolumn{3}{|c|}{$\begin{array}{l}\text { Polymer-cement mortar PCC (A) } D_{\max }=2,0 \mathrm{~mm} \\
3 \mathrm{~cm}\end{array}$}} & \multirow{2}{*}{\multicolumn{3}{|c|}{$\begin{array}{l}\text { Polymer-cement mortar PCC (B) } D_{\max }=0,25 \mathrm{~mm} \\
3 \mathrm{~cm}\end{array}$}} \\
\hline Repair layer thickness & & & & & & \\
\hline
\end{tabular}



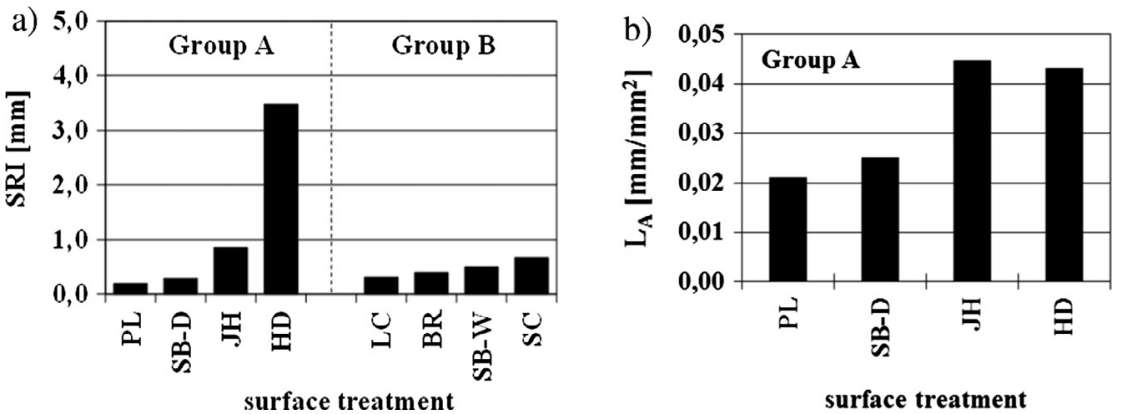

Fig. 3. Surface Roughness Index, SRI (a) and density of microcracks, $L_{A}$ (b) versus surface treatment (acc. to [19]).
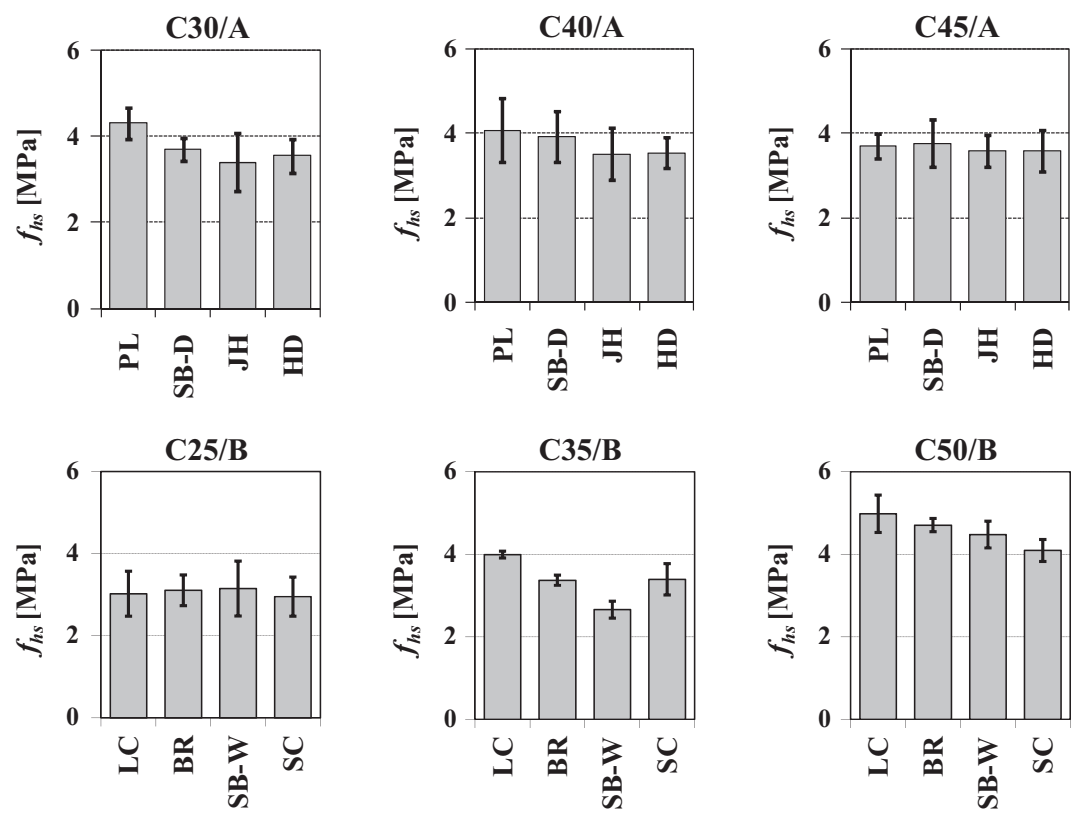

Fig. 4. Surface tensile strength, $f_{h s}$ of samples (acc. to [19]).
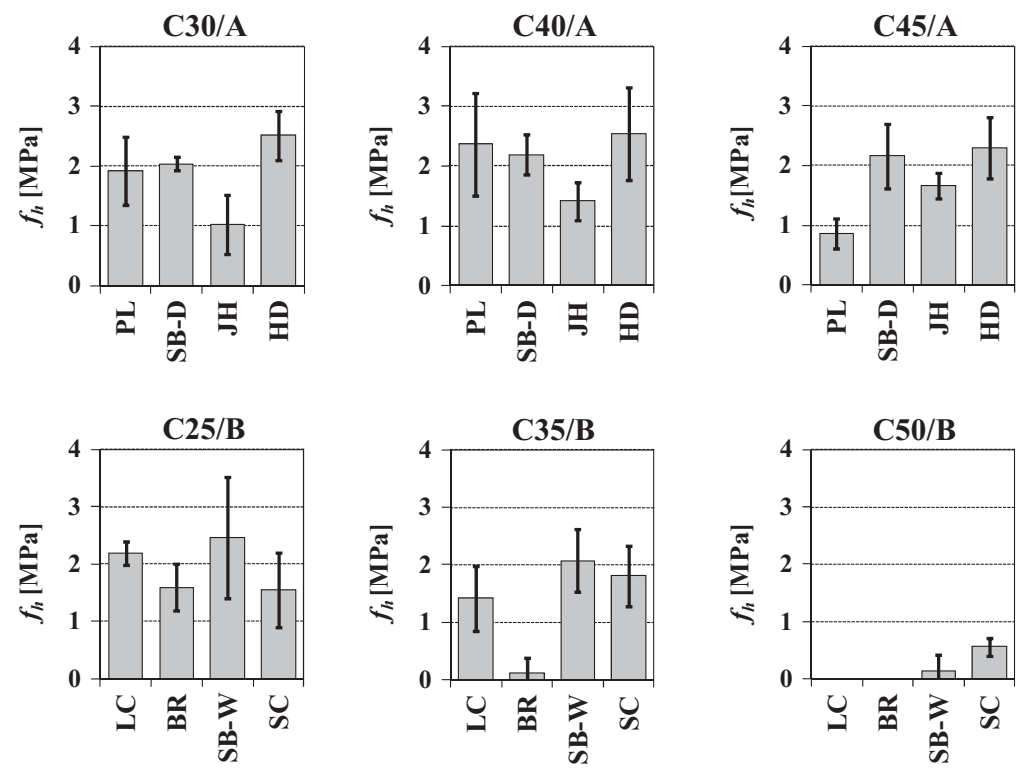

Fig. 5. Pull-off bond strength, $f_{h}$ of samples (acc. to [19]). 
of a steel ball on the surface [11]. The impact is generating stress waves that propagate through the structure and are reflected by interfaces within the material (internal flaws such as voids, honeycombs, cracks and delamination) or external boundaries. As stress waves are of low frequency (mainly below $60 \mathrm{kHz}$ ). IE method is often used for quality control of various types of repair, e.g. injection of cable ducts, overlays etc. (eg.[10,20-22]). Additional feature of IE method besides a time-domain analysis is frequency analysis. Based on frequency spectrum, the depth of the reflecting interface (e.g. flaws) can be determined according to formula Eq. (1):

$d=\frac{\beta \cdot c_{p}}{2 \cdot f_{d}}$

where: $d$ - depth of interface, $c_{p}$ - wave velocity, $f_{d}$ - frequency of dominant peak, $\beta$ - shape factor $(\beta=0.96$ in the case of plate structures).

There are also some limitations to the use of IE for detecting defects [11]:

- minimal depth of defect $d[\mathrm{~mm}]$ results from basic relation between wave velocity $c_{p}[\mathrm{~m} / \mathrm{s}]$ and maximum frequency of useful energy $f[\mathrm{kHz}]$ that is directly connected to ball diameter (Fig. 6);

- minimal lateral dimension $L_{\min }[\mathrm{mm}]$ of defect should be bigger than minimal wave length $\lambda_{\min }[\mathrm{mm}]$ (see Fig. 6);

- minimal lateral dimension $L_{\min }[\mathrm{mm}]$ of defect should be at least 0.25 and no more than 1.5 times the depth $d[\mathrm{~m}]$.

Taking into account these conditions impact ball diameter of $2 \mathrm{~mm}$ was selected to evaluate interface quality in both types of repair systems. For the analyzed systems, composed of a $10 \mathrm{~cm}$ (Group A) or $7 \mathrm{~cm}$ (Group B) thick concrete substrate and a $3 \mathrm{~cm}$ thick repair layer, the possible shapes of a frequency spectrum for a repaired system with defect at interface are presented in Fig. 6. If a defect is sufficiently large $\left(>28 \mathrm{~mm}\right.$ at $\left.c_{p}=4000 \mathrm{~m} / \mathrm{s}\right)$ there is no bottom (opposite surface) peak $\left(A_{b}\right)$ observed but only a clear interface peak $\left(A_{i}\right)$ is present; frequency spectrum is like for an element of thickness equal to defect depth (Fig. 6a). When a defect is smaller a clear bottom $\left(A_{b}\right)$ and an interface peak $\left(A_{i}\right)$ are visible in frequency spectrum (Fig. 7b). In an extreme situation,

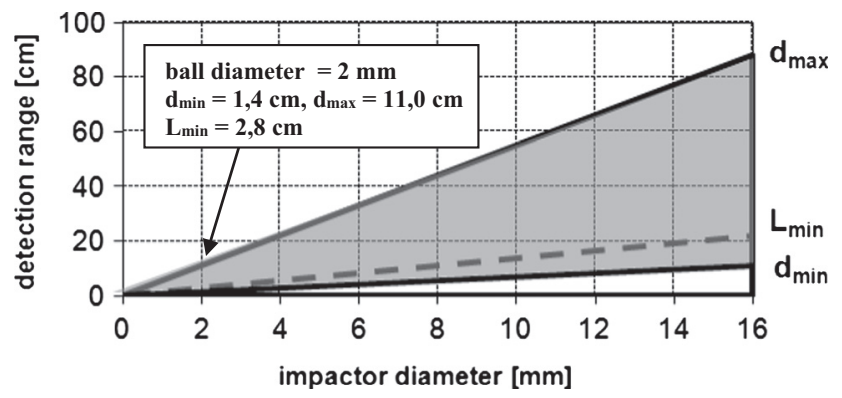

Fig. 6. IE method detection range vs. impactor diameter.

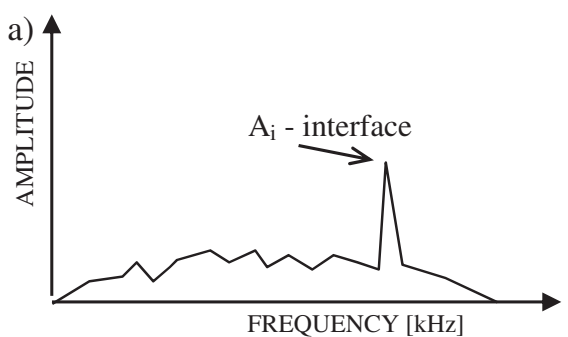

when a delamination is very wide and located close to the surface, a flexural vibration peak of a high amplitude and low frequency dominates in the spectrums.

The effect of interface quality on frequency spectrum was observed by Garbacz [23] during testing repair systems with ultrasonic pulse echo method (nominal frequency of transducer $500 \mathrm{kHz}$ ). The test results indicated that there was no correlation between the pull-off strength and the P wave velocity for the repair system with bond coat. The bond coat filled properly irregularities of concrete substrate properly and air voids at the interface were not observed. The statistically significant relationship was obtained for systems without the bond coat - the P wave velocity increased as the pull-off strength increased. In this case, the fraction of air voids at the interface increased when the roughness increased. In both types of repair systems the pulse velocity was not correlated with the substrate roughness. The trend was found in studying the relationship between the amplitude of maximum frequency peak and the pull-off strength: as the pull-off strength increases, the amplitude value of peak decreases. Statistical significance of the relationship between the amplitude value of the highest peak and the mean waviness of surface profile (Fig. $5 \mathrm{~d}$ ) was also found but only for the repair systems without the bond coat, essentially because the fraction of air voids increased with the surface roughness.

The effect of substrate surface roughness on ultrasonic wave propagation was analyzed by Santos et al. [24] as well. Their FEM simulation indicated that roughness of concrete substrate had relatively low influence on signal amplitude. However, they observed that these pulses decrease in the presence of rough interfaces, due to a greater wave dispersion. In the case of presence of heterogeneous concrete layers, significant noise appears in the signal, generated by the coarse aggregates, masking the echo differences previously detected between smooth and rough interfaces.

Taking into account principles of IE method it seems to be possible to assume that generated stress waves should be less sensitive on surface roughness and amplitude of peaks in frequency spectrum could reflect bond strength in repair systems.

By analogy to the ultrasonic pulse-echo methods, it seems to be possible to correlate interface quality with the amplitude of the characteristic peaks in the frequency spectrum. These peaks appear at the frequency range corresponding to the reflected wave from the interface and/or the opposite surface of the concrete slab (bottom peaks). It can be expected that, in the case of lowquality repair in the frequency spectrum will be present a peak of relatively high amplitude corresponding to the interface reflection - simultaneously the amplitude of the bottom peak will decrease.

\section{Results analysis}

Results of IE measurements for tested samples were presented in the form of maps of the frequency spectrum (Fig. 8) in the fol-

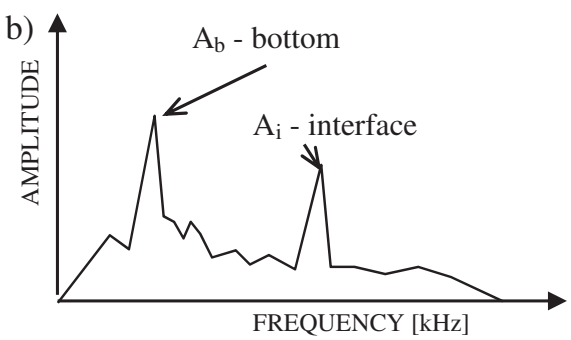

Fig. 7. Typical shapes of a frequency spectrum for a system with defects at interface. 
C30-SB-D: $f h=2,04 \mathrm{MPa}, S D=0,11 \mathrm{MPa}$

a)

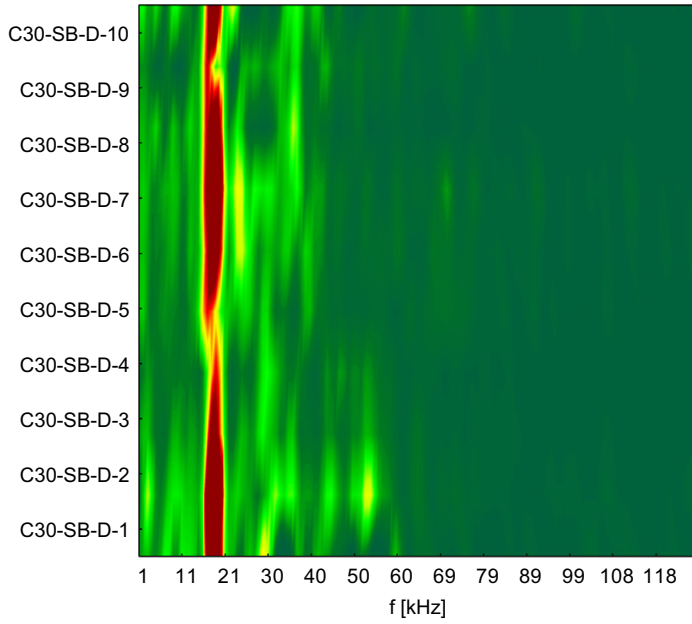

C30-PL: $f h=1,91 \mathrm{MPa}, S D=0,57 \mathrm{MPa}$

b)

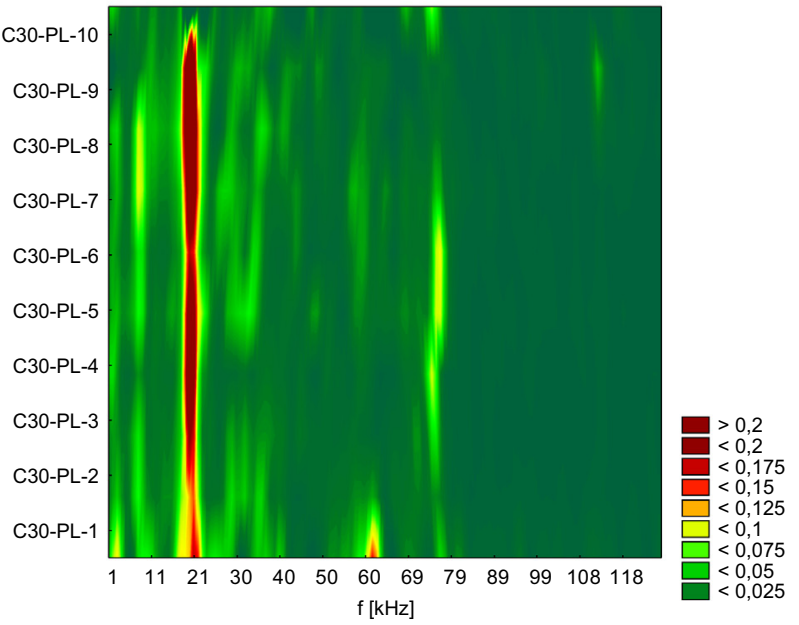

C50-BR: $f h=0,00 \mathrm{MPa}, S D=0,00 \mathrm{MPa}$

c)

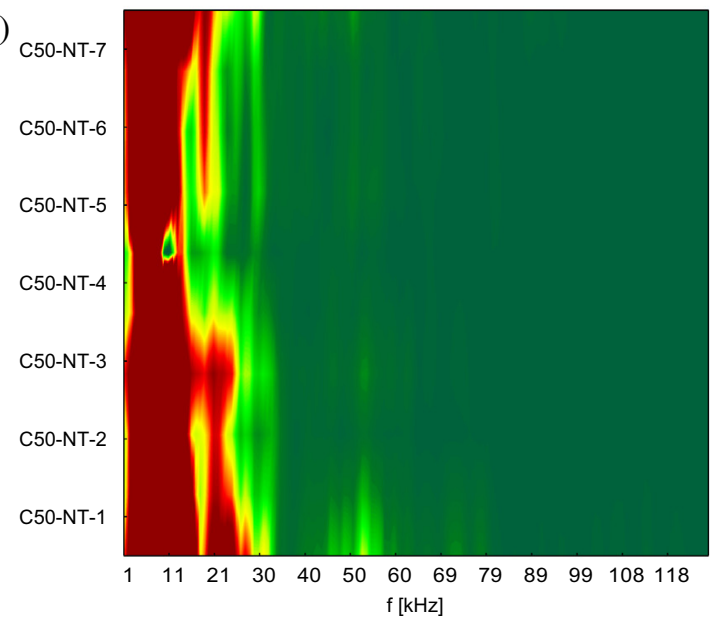

C35-SB-W: $f h=2,08 \mathrm{MPa}, S D=0,54 \mathrm{MPa}$

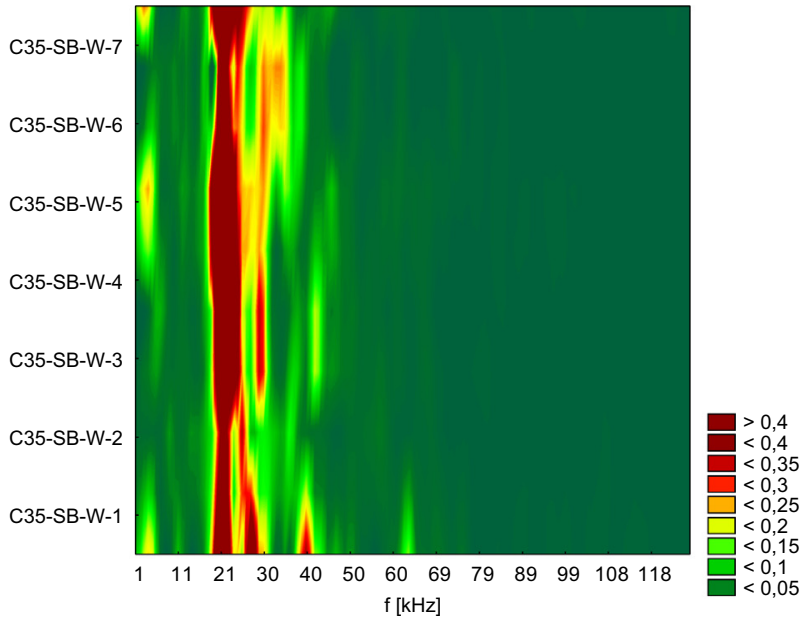

C40-PL: $f h=2,36 \mathrm{MPa}, S D=0,85 \mathrm{MPa}$

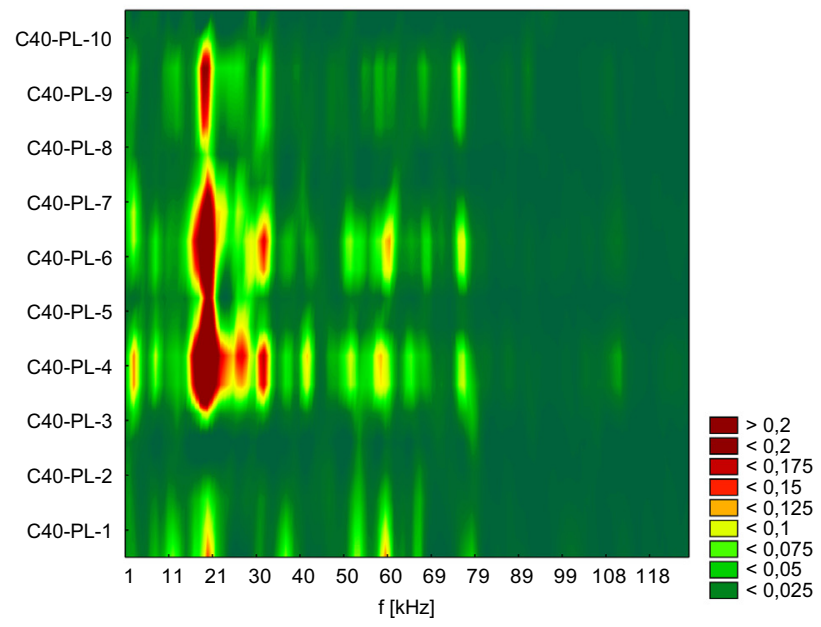

C50-LC: $f h=0,00 \mathrm{MPa}, S D=0,00 \mathrm{MPa}$

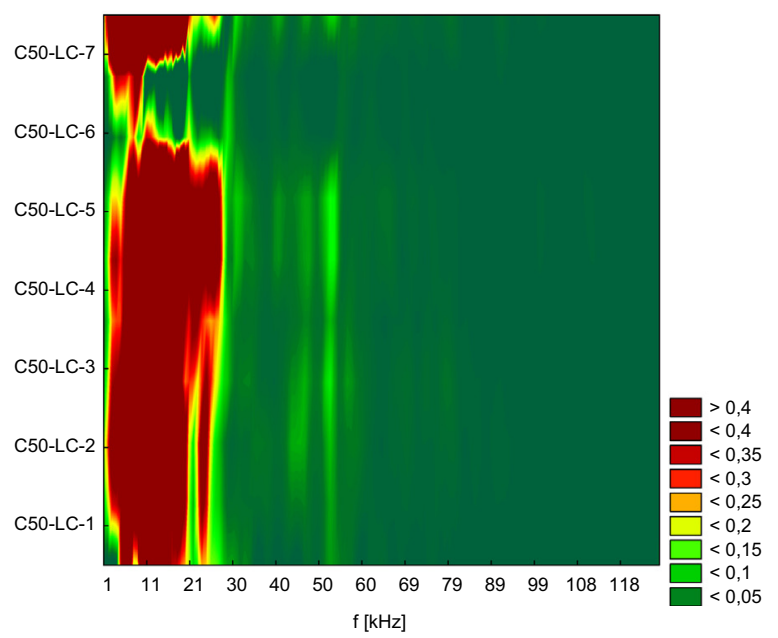

Fig. 8. Examples of IE frequency spectrum maps for: C30A-SB-D and C35B-SB-W (a) C30A-PL and C40A-PL (b) C50B-BR and C50B-LC (c).

lowing axes configurations: $\mathrm{X}$ - frequency [kHz], Y number of measurements on the sample (Group A 1-10; Group B 1-7). The colors correspond to the amplitude in the spectrum of frequencies. Spectra obtained in the study of systems for the Group A, where the range of substrate surface roughness is larger, are more heteroge- neous than the spectra obtained in the study of systems for Group $B$ with less rough profile. For almost all systems, the characteristic peak, corresponding to the reflected wave from the lower surface of the concrete slab (bottom) is visible at frequencies around $20 \mathrm{kHz}$ (Fig. 7a,b). Only in two cases, for systems C50-LC and 
C50-BR (Fig. 8c), significant peaks in the low frequencies - below $11 \mathrm{kHz}$, are dominant. This was confirmed when coring samples for pulloff test where a lack of adhesion of repair material was observed.

For the tested repair systems, mean values of maximal amplitudes in two specific ranges of the frequency spectra were analyzed based on the wave speed evaluation and repair system geometry: first range was around the bottom peak frequency $f_{b}$ and second one around frequencies corresponding to the interface $f_{i}$ - the values of the ranges are presented in Table 2 .

Although standard deviations of amplitude values $\left(A_{b}\right.$ and $\left.A_{i}\right)$ are large (Table 3 ), some general observations, especially for Group A, can be drawn. A number of factors affecting on bond quality have an effect on the amplitudes of characteristics peaks in frequency spectrums but not always in the same direction. These dependences may be clearly observed on spectrums for samples of group A presented in Fig. 8. The mean values of bottom peak $A_{b}$ are the lowest for polishing and hydrodemolition (Fig. 8a,d). In the first case, this is probably due to either delamination or cracks parallel to the interface [15]. A different explanation is given in the case of hydrodemolition: it was observed that very rough surface (the biggest SRI) was not filled with the repair mortar and air voids at the interface were entrapped. The amplitude of interface peak $A_{i}$ was again the highest for polished and jack-hammered samples (Fig. 9a,d). Moreover, samples after hydrodemolition presented a multi-peak shape in the range of frequencies corresponding to reflection from the interface. The lowest value was obtained for sandblasted samples - here neither microcracks nor air voids were observed. In case of group B, the amplitudes for LC samples are usually the highest but no other relations are observed.

Next step was to find relations between the analyzed peak amplitudes and pull-off bond strength. The multiple regression correlation results, presented in Table 4 , for the explanatory variables $A_{i}$ and $A_{b}$ do not show statistical relation to bond strength fh (correlation coefficient $\mathrm{R}$ is much less than 1.0 and statistical significance of a result $p>0.05$ ). However, the results indicate that the amplitude $A_{b}$ more largely contributes to the explanation of the level of bond strength than the amplitude $A_{i}$ (a larger standardized regression coefficient $\beta$ is for $A_{b}$ ). It was surprising, as it was expected that information about the bond quality would come rather in the frequency corresponding to the wave reflected from the interface $\left(A_{i}\right)$ than from the bottom $\left(A_{b}\right)$.

Nevertheless in the following multiple regression correlation analysis, the roughness and the microcracking level, which affect the elastic wave propagation, were taken into account. SRI and fhs, two parameters whose statistical significance was already demonstrated by Courard et al. [19], have been introduced into the correlation model. As a result multiple regression correlation coefficients R increased up to 0.70 for Group A and 0.85 for Group $B$ respectively, as presented in Table 5.

Results show that the amplitudes of characteristic peaks are related not only to the level of bond, but also to the roughness and microcracking as well. Several high peaks in the range corresponding to the interface, observed in the case of the hydrodemolition treatment (HD), as well as shifted maximum peak towards lower frequencies in the spectrum for the jack hammered sample

Table 2

Frequency ranges for bottom, $\mathrm{f}_{\mathrm{b}}$, and interface, $\mathrm{f}_{\mathrm{i}}$, peaks.

\begin{tabular}{|c|c|c|c|c|c|}
\hline \multirow[t]{2}{*}{ Peak } & \multirow[t]{2}{*}{ Unit } & \multicolumn{2}{|c|}{ Group A } & \multicolumn{2}{|c|}{ Group B } \\
\hline & & From & To & From & To \\
\hline$f_{b}$ & {$[\mathrm{kHz}]$} & 14.65 & 19.53 & 17.58 & 22.46 \\
\hline$f_{i}$ & {$[\mathrm{kHz}]$} & 58.59 & 87.89 & 42.97 & 72.27 \\
\hline
\end{tabular}

Table 3

Amplitudes of characteristic IE frequency peaks for specified concrete repair systems of Group A and B.

\begin{tabular}{|c|c|c|c|c|}
\hline \multirow[t]{2}{*}{ Sample } & \multicolumn{2}{|l|}{$\mathrm{A}_{\mathrm{b}}$} & \multicolumn{2}{|l|}{$\underline{A_{i}}$} \\
\hline & Mean & SD & Mean & SD \\
\hline \multicolumn{5}{|l|}{ GROUP A } \\
\hline C30-PL & 0.25 & 0.17 & 0.067 & 0.035 \\
\hline C40-PL & 0.18 & 0.15 & 0.058 & 0.043 \\
\hline C45-PL & 0.14 & 0.04 & 0.025 & 0.011 \\
\hline C30-SB-D & 0.32 & 0.17 & 0.017 & 0.008 \\
\hline C40-SB-D & 0.16 & 0.09 & 0.028 & 0.024 \\
\hline C45-SB-D & 0.20 & 0.16 & 0.032 & 0.014 \\
\hline C30-JH & 0.36 & 0.18 & 0.063 & 0.079 \\
\hline C40-JH & 0.12 & 0.07 & 0.019 & 0.014 \\
\hline C45-JH & 0.43 & 0.19 & 0.081 & 0.040 \\
\hline C30-HD & 0.19 & 0.08 & 0.057 & 0.041 \\
\hline C40-HD & 0.11 & 0.08 & 0.019 & 0.021 \\
\hline C45-HD & 0.20 & 0.14 & 0.032 & 0.017 \\
\hline \multicolumn{5}{|l|}{ GROUP B } \\
\hline C25-LC & 1.01 & 0.58 & 0.051 & 0.025 \\
\hline C35-LC & 1.24 & 0.79 & 0.169 & 0.119 \\
\hline C50-LC & 0.88 & 0.84 & 0.083 & 0.049 \\
\hline C25-BR & 0.58 & 0.32 & 0.022 & 0.007 \\
\hline C35-BR & 0.89 & 0.38 & 0.062 & 0.047 \\
\hline C50-BR & 0.32 & 0.11 & 0.048 & 0.035 \\
\hline C25-SB-W & 0.32 & 0.15 & 0.031 & 0.011 \\
\hline C35-SB-W & 0.88 & 0.22 & 0.066 & 0.027 \\
\hline C50-SB-W & 1.07 & 0.52 & 0.043 & 0.023 \\
\hline C25-SC & 0.64 & 0.36 & 0.039 & 0.022 \\
\hline C35-SC & 0.37 & 0.15 & 0.019 & 0.009 \\
\hline C50-SC & 0.86 & 0.33 & 0.036 & 0.016 \\
\hline
\end{tabular}

SD - standard deviation. 
a) PL

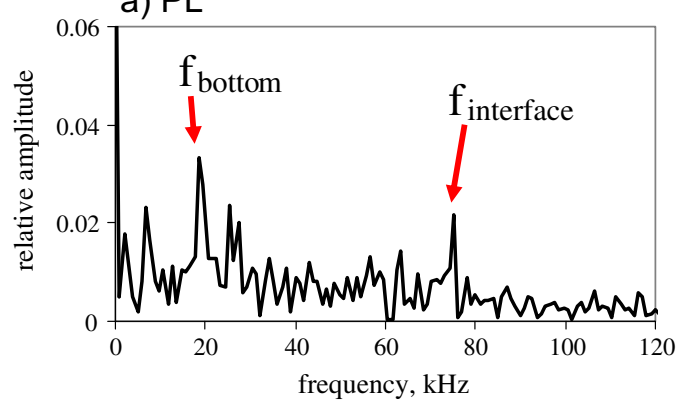

c) $\mathrm{JH}$

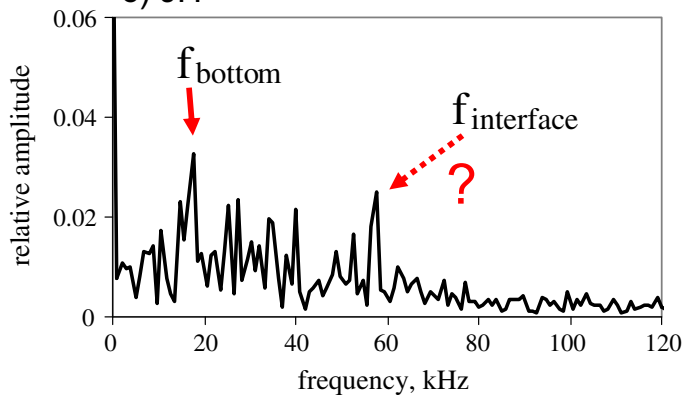

b) SB-D

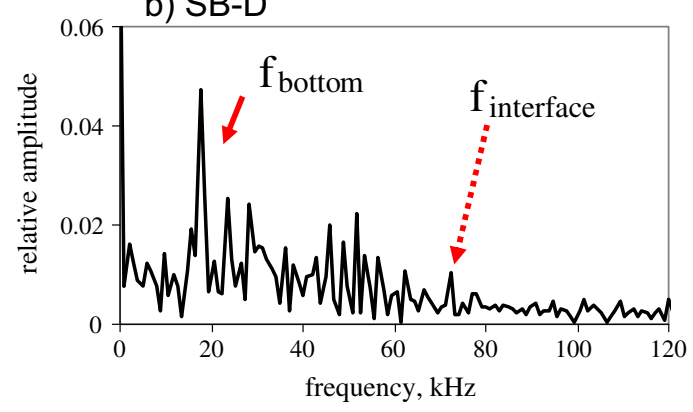

d) HD

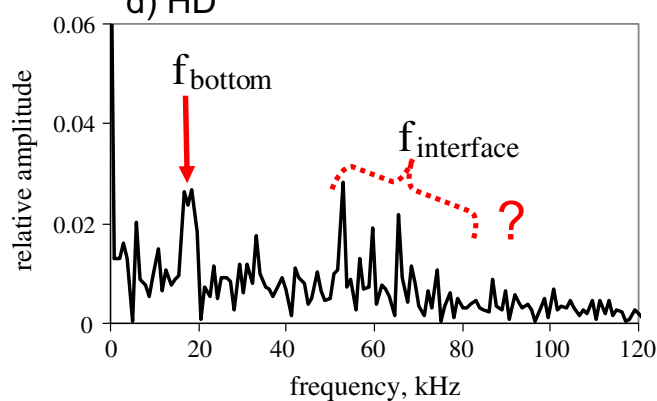

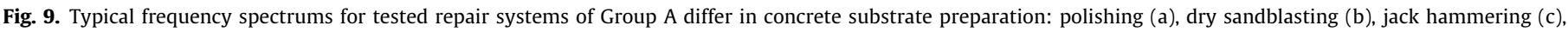
hydrodemolition (d).

Table 4

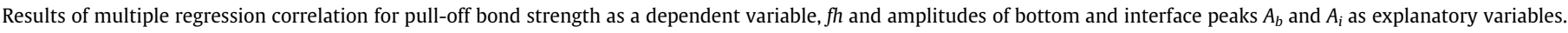

\begin{tabular}{|c|c|c|c|c|c|c|c|c|c|c|c|}
\hline \multirow[t]{2}{*}{$\mathrm{n}=12$} & \multicolumn{5}{|c|}{$\begin{array}{l}\text { Group A } \\
\mathrm{R}=0.29 ; \mathrm{R}^{2}=0.08 ; p<0.68 ; B S E=0.59\end{array}$} & \multirow[t]{2}{*}{$\mathrm{n}=12$} & \multicolumn{5}{|c|}{$\begin{array}{l}\text { Group B } \\
\mathrm{R}=0.19 ; \mathrm{R}^{2}=0.04 ; p<0.84 ; B S E=1.01\end{array}$} \\
\hline & $\beta$ & $\mathrm{SD} \beta$ & $B$ & $\mathrm{SD} B$ & $p$ & & $\beta$ & $\mathrm{SD} \beta$ & $B$ & $\mathrm{SD} B$ & $P$ \\
\hline$A_{b}$ & -0.364 & 0.421 & -2.067 & 2.396 & 0.411 & $A_{b}$ & -0.203 & 0.435 & -0.621 & 1.326 & 0.651 \\
\hline$A_{i}$ & 0.152 & 0.421 & 3.873 & 10.710 & 0.726 & $A_{i}$ & 0.017 & 0.435 & 0.402 & 10.086 & 0.969 \\
\hline intercept & & & 2.210 & 0.448 & 0.001 & intercept & & & 1.606 & 0.812 & 0.079 \\
\hline
\end{tabular}

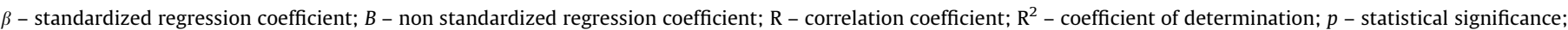
$\mathrm{SD}$-standard deviation for variable; BSE - standard deviation for fh estimation [MPa].

Table 5

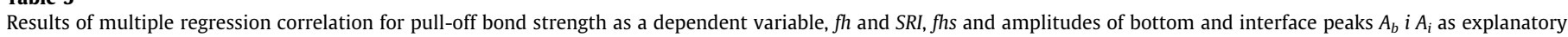
variables.

\begin{tabular}{|c|c|c|c|c|c|c|c|c|c|c|c|}
\hline \multirow[t]{2}{*}{$n=12$} & \multicolumn{5}{|c|}{$\begin{array}{l}\text { Group A } \\
\mathrm{R}=0.70 ; \mathrm{R}^{2}=0.49 ; p<0.26 ; B S E=0.50\end{array}$} & \multirow[t]{2}{*}{$\mathrm{n}=12$} & \multicolumn{5}{|c|}{$\begin{array}{l}\text { Group B } \\
\mathrm{R}=0.85 ; \mathrm{R}^{2}=0.71 ; \mathrm{p}<0.44 ; \mathrm{BSE}=0.63\end{array}$} \\
\hline & $\beta$ & $\operatorname{SD} \beta$ & $B$ & $\mathrm{SD} B$ & $p$ & & $\beta$ & $\mathrm{SD} \beta$ & $B$ & SD $B$ & $p$ \\
\hline SRI & 0.765 & 0.337 & 0.283 & 0.125 & 0.057 & fhs & -0.830 & 0.244 & -1.011 & 0.297 & 0.011 \\
\hline fhs & 0.631 & 0.349 & 1.355 & 0.749 & 0.113 & $A_{i}$ & 0.289 & 0.277 & 6.716 & 6.432 & 0.331 \\
\hline$A_{b}$ & 0.109 & 0.415 & 0.619 & 2.358 & 0.801 & $A_{b}$ & -0.246 & 0.284 & -0.752 & 0.865 & 0.414 \\
\hline$A_{i}$ & -0.101 & 0.389 & -2.557 & 9.879 & 0.803 & SRI & 0.0 .53 & 0.264 & 0.276 & 1.383 & 0.847 \\
\hline intercept & & & -3.495 & 2.987 & 0.280 & intercept & & & 4.920 & 1.754 & 0.026 \\
\hline
\end{tabular}

$\beta$ - standardized regression coefficient; $B$ - non standardized regression coefficient.

$\mathrm{R}$ - correlation coefficient; $\mathrm{R}^{2}$ - coefficient of determination; $p$ - statistical significance.

SD -standard deviation for variable; BSE - standard deviation for fh estimation [MPa].

$(\mathrm{JH})$, confirm this conclusion. It means that the maximum amplitudes of the characteristic peaks are the parameters insufficient and inaccurate for bond strength evaluation in repair systems. It leads to the research on use of more advanced signal analysis, e.g. wavelet analysis.

\section{Finite Element model analysis}

Numerical time-domain studies were carried out using Finite Element (FE) code LS-DYNA ${ }^{\circledR}$, dedicated to transient dynamic problems based on the model developed by Kwaśniewski and Garbacz [25]. The FE models were dedicated to large plates which can be treated locally (in vicinity of the impact point) as a part of infinite (in two dimensions) media. These FE models refer to an infinite plate with total thickness of $200 \mathrm{~mm}$. It consists of 6 layers - five upper layers, each with thickness of $20 \mathrm{~mm}$, can have different material properties (Fig. 10). The last, bottom layer of thickness $100 \mathrm{~mm}$ is supposed to represent concrete substrate. The FE models represent segments of the cylinder with radius $260 \mathrm{~mm}$, cut off about the vertical axis positioned along the 
impact direction. The FE meshes are built with regular wedge sixnode and cubic eight node elements, each with mostly the same vertical dimension of $2 \mathrm{~mm}$. The quarter model consists of 276,050 elements. Symmetry boundary conditions were defined on the vertical cross-sectional planes, were normal displacements were constrained. Nonreflecting boundaries are applied to the cylindrical surface to represent the connection to the infinite media.

The simulations with that model have shown that repair material thickness as well as its acoustic properties are the important factors influencing propagation of stress wave through repair system. Numerical investigations of IE method have shown that an interface is usually "visible" if absolute value of $\mathrm{R}$ coefficient is higher than $+0.24[10,25]$. This was also experimentally confirmed by Garbacz for polymer-cement composites differ in polymer content [23].
The above FE model was modified to simulate effect of substrate roughness and presence of air voids at the interface on stress wave propagation. The simulations were performed for system with the same profile geometry as the ones used in the experiment and for two extreme cases of filing of surface irregularities: completely filled and non-filled surface irregularities (Fig. 11). The surface geometry corresponded to real surfaces roughness obtained after sandblasting (SB) and hydrodemolition under high pressure (HD) of concrete substrate of compressive strength class C40/50.

The experimental tests were carried out on $600 \times 800 \mathrm{~mm}$ rectangular plates and $130 \mathrm{~mm}$ total thickness (concrete substrate $100 \mathrm{~mm}$ and overlay $-30 \mathrm{~mm}$ ). The material properties (E modulus and density) of the both concrete substrate and overlay were determined. The simulation performed for solid concrete plates with the same geometry confirmed that it can be considered as the infinite medium (Fig. 12).
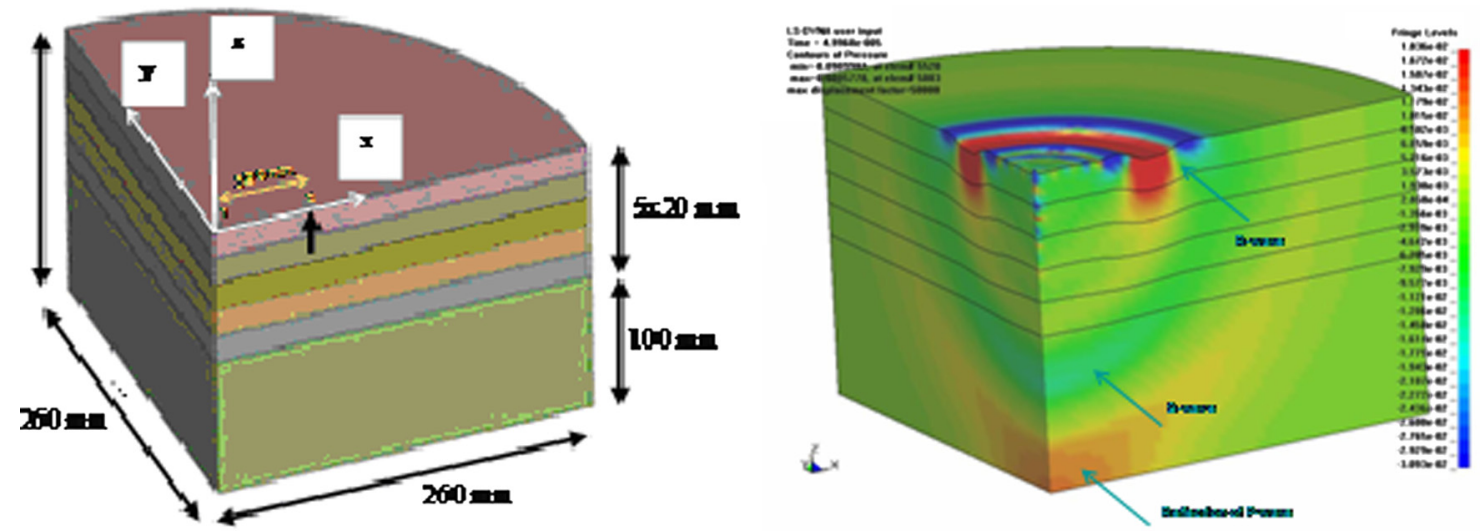

Fig. 10. FE models of quarter the cylindrical segment used for simulation of effect of repair overlay properties and corresponding contours of pressure.
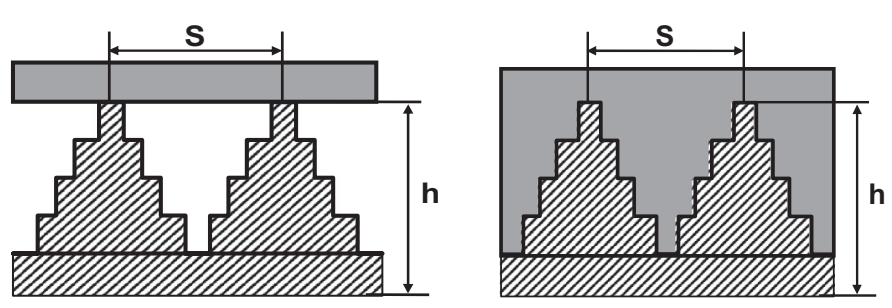

\begin{tabular}{|c|c|c|}
\hline Sample & $\mathrm{S}[\mathrm{mm}]$ & $\mathrm{H}[\mathrm{mm}]$ \\
\hline Simulation SB-D & 4 & 2 \\
\hline Simulation HD & 8 & 8 \\
\hline
\end{tabular}

Fig. 11. Assumed roughness patterns description with completely filled and non-filled surface irregularities in FEM simulations.
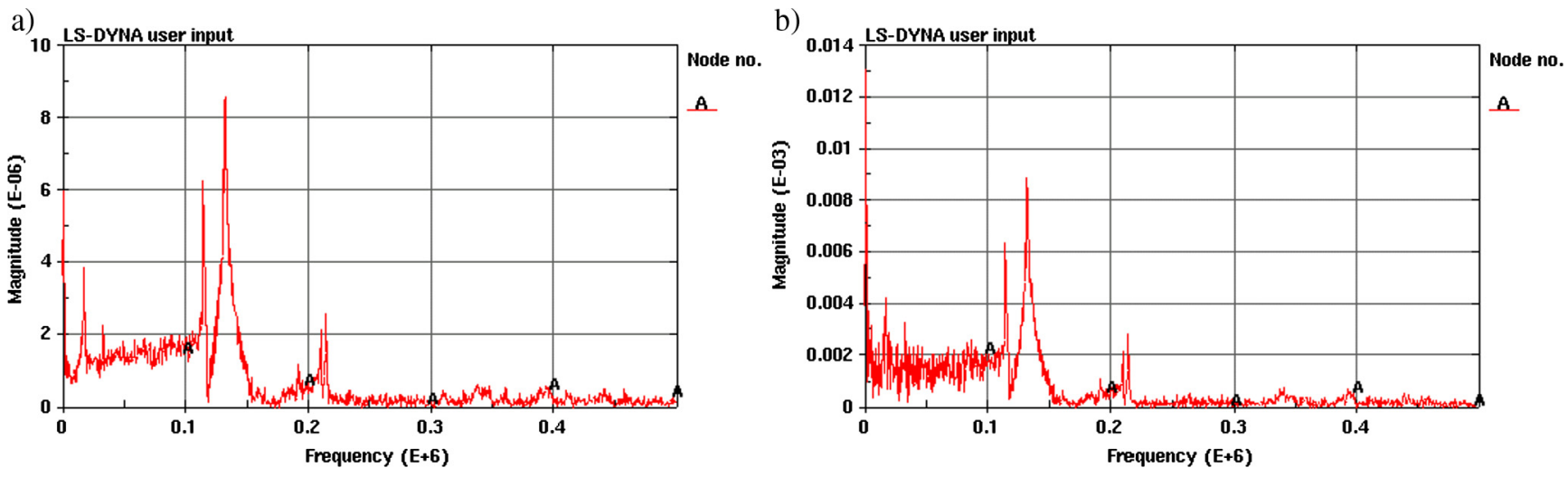

Fig. 12. Comparison of amplitude spectra for (a) infinite medium and (b) solid concrete plate with dimensions: $600 \times 800 \times 130 \mathrm{~mm}$. 

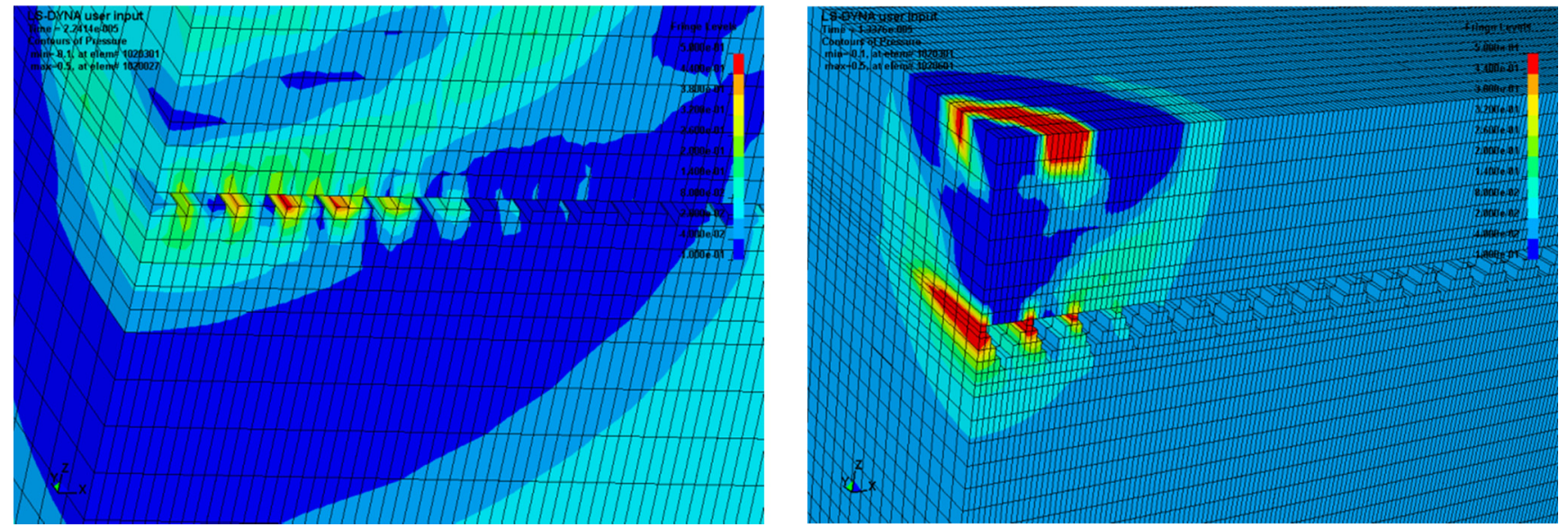

Fig. 13. Example of disturbance in wave propagation for sandblasted (a) and hydrodemolitioned (b) surfaces in the case of air voids presence at interface.

The grooves are oriented along y length direction. The meshes are built of regular hexagonal eight-node elements with typical xyz dimensions of $1 \times 4 \times 2 \mathrm{~mm}$. The height of the elements in the interface was reduced to $1 \mathrm{~mm}$ for modelling substrate roughness and voids. The quarter model consists of over 1.1 million of finite elements. Similarly to the first group of the FE models, symmetry boundary conditions were defined on the vertical crosssectional planes, were normal displacements were constrained. In the vertical direction the modelled segment is supported only a few nodes located in the bottom corner of the plate. This local supports against vertical displacement, simulate the actual test conditions. There are eight nodes identified for displacement reading. These nodes are located on the top surface with $20 \mathrm{~mm}$ spacing along $\mathrm{x}$-axis (shorter side). Time histories of displacement for the second node, $20 \mathrm{~mm}$ from the impact point, represent basic detected signal.

The results of simulation indicate presence of larger air voids at the interface. They can significantly influence stress wave propagation

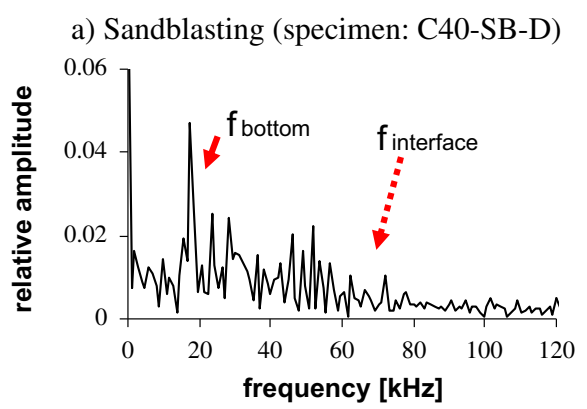

c) FEM simulations: sandblasted substrate

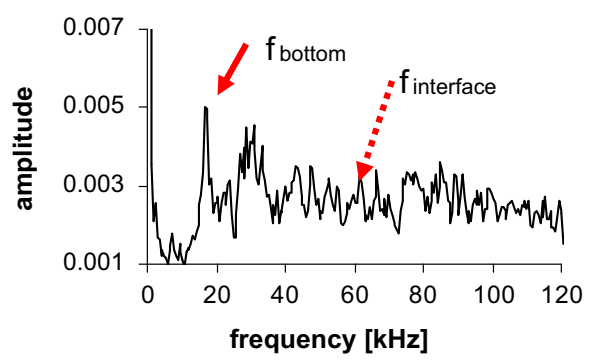

e) Simulation SB-D_p

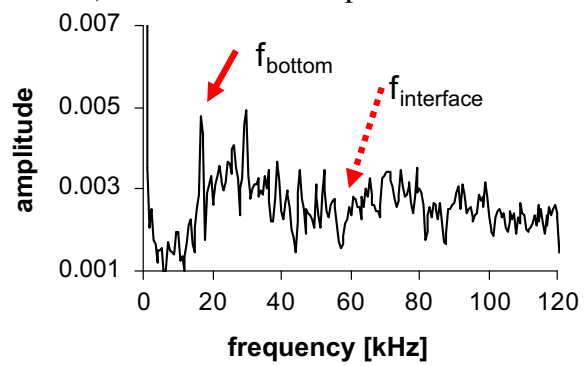

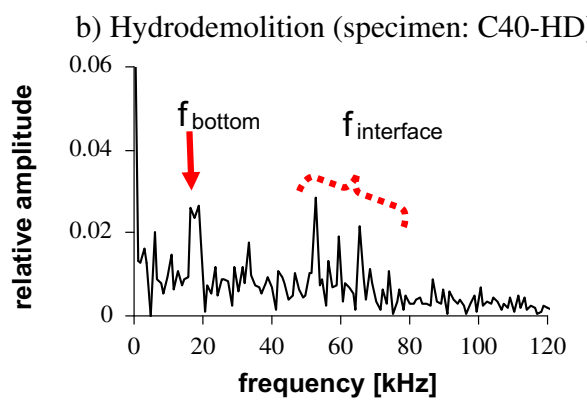

d) FEM simulations: substrate after hydrodemolition

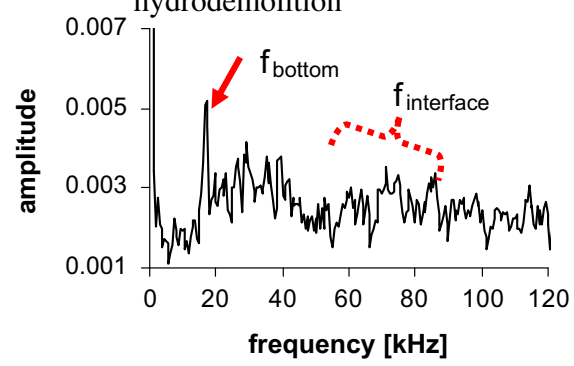

f) Simulation HD_p

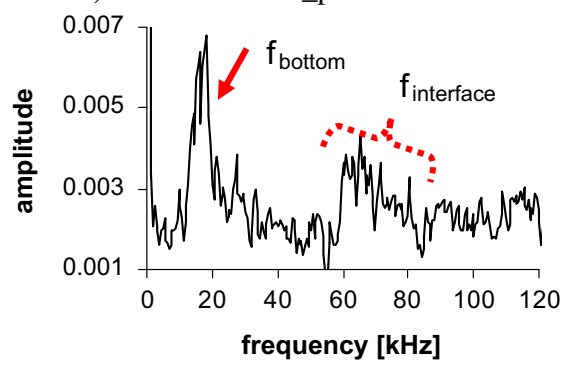

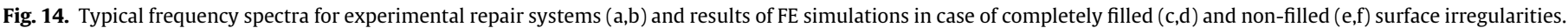


even in the case of long wave as generated in IE method (Fig. 13). If surface profile irregularities are filled the surface roughness does not significantly influence the shape of frequency spectrum.

Frequency spectra resulted from FE simulations and experimental program (Group A SB-D and HD) indicate good similarity, especially in the case of possible air voids at the interface (Fig. 14b,f). It can be concluded that the presence of larger air voids at the interface significantly influence the propagation of stress waves in repair systems.

\section{Wavelet approach}

As it was introduced in chapter 4 more complex IE signal analysis can be helpful for bond strength estimation in repair systems. A new tool for signal analysis - wavelet multiresolution time-scale method was recently implemented in NDT for concrete structures

Table 6

Pseudo-frequencies for details of levels 1 to 6 for wavelet transform (sampling $\Delta=2 \mu \mathrm{s})$.

\begin{tabular}{llll}
\hline Scale & Detail level & \multicolumn{2}{l}{ Pseudo-frequency $f_{a}[\mathrm{kHz}]$} \\
\cline { 3 - 4 } & & $\mathrm{db} 2$ (called Haar) & $\mathrm{db} 4$ \\
\hline 2 & $\mathrm{~d} 1$ & 249 & 179 \\
4 & $\mathrm{~d} 2$ & 125 & 89 \\
8 & $\mathrm{~d} 3$ & 62 & 45 \\
16 & $\mathrm{~d} 4$ & 31 & 22 \\
32 & $\mathrm{~d} 5$ & 16 & 11 \\
64 & $\mathrm{~d} 6$ & 8 & 6 \\
\hline
\end{tabular}

a) $\mathrm{C} 40-\mathrm{PL}$

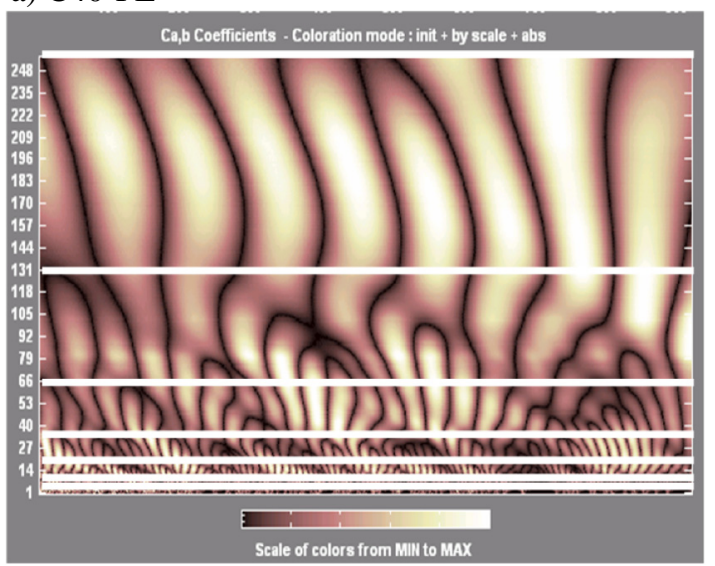

c) $\mathrm{C} 40-\mathrm{JH}$

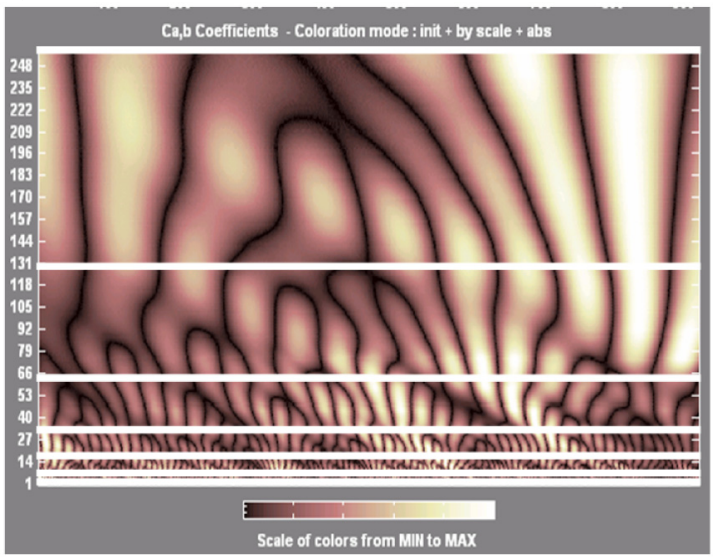

assessment [26-28]. It presents the next logic step in frequency analysis of signals - a STFT method of flexible size windows. It allows using long or short time sections, when analysis of low and high frequencies is made respectively. In comparison with STFT, the result image is divided on time-scale segments that are of different sizes depending on scale range. This effect is a result of using, instead of sine function, a wavelet - "short" wave, well concentrated in both time and frequency. A Wavelet Toolbox in MatLab environment was used here for analyses [29].

Wavelet analysis allows for a decomposition of a signal on a set of shifted and scaled versions of mother wavelet. Continuous Wavelet Transform - CWT is resulting into C coefficients that are functions of scale and time position: a signal is composed of a sum of shifted and scaled wavelet multiplied by C. CWT is usually presented as a time-scale graph called scalogram.

If we use scaling parameters of powered 2 the Discrete Wavelet Transform - DWT is used. In practice, it is realized be using low and high-pass filters. Filtering process decomposes signal into the approximation (low frequency content) and details - a set of coefficient/time diagrams on given scale levels 2, 4, 8, 16 etc. (high frequency components).

First step of the wavelet analysis is to select proper function wavelet. As it was intended to make both CWT and DWT analysis the possibilities are limited to orthogonal and biortogonal wavelets. Next recommendation is to use wavelet being the most similar to a signal that is going to be analyzed. As IE signal is not symmetric and the resolution is not limited - the best choice

\section{b) C40-SB-D}

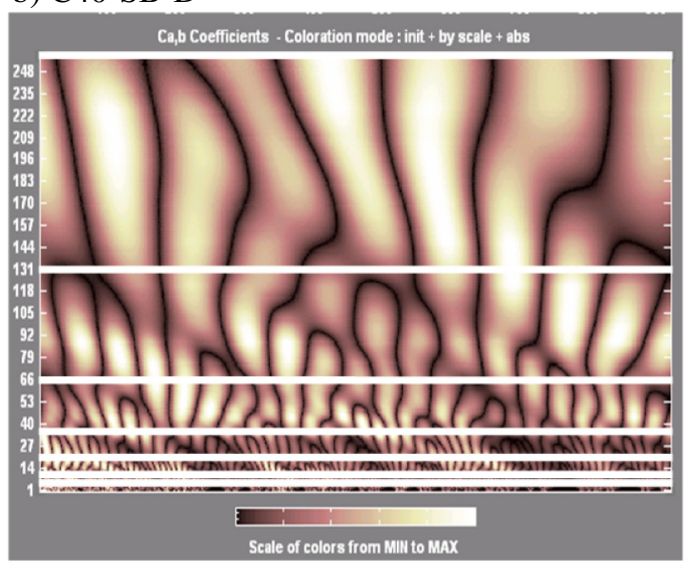

d) $\mathrm{C} 40-\mathrm{HD}$

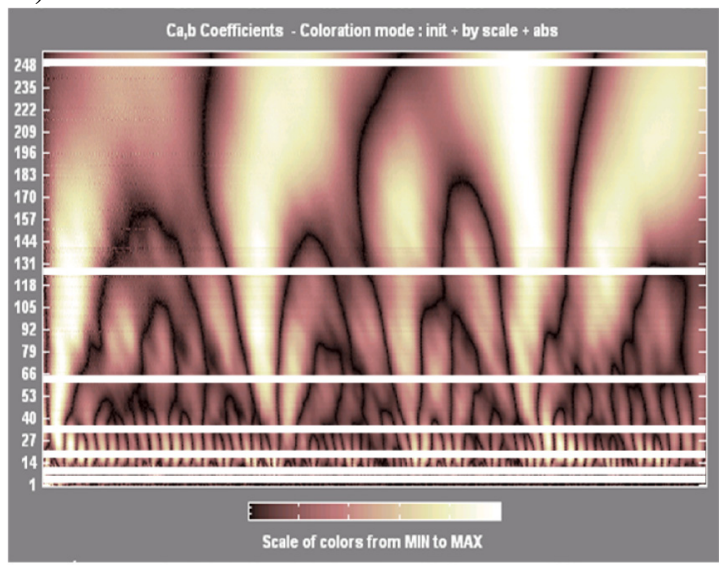

Fig. 15. Typical scale-time diagrams for tested repair systems of Group A with different concrete substrate preparation: (a) polishing, (b) dry sandblasting, (c) jack hammering, (d) hydrodemolition. 
a) Simulation SB-D

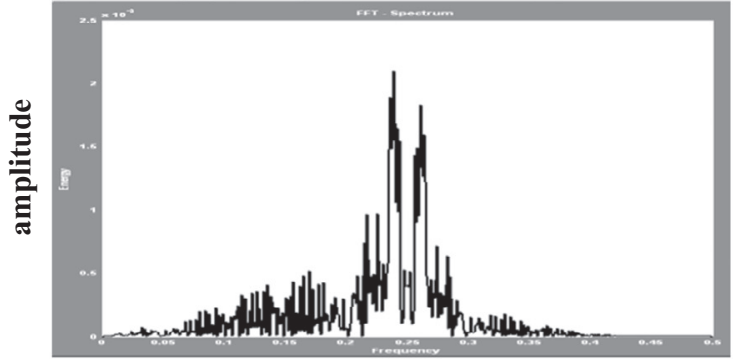

frequency $[\mathrm{kHz}]$

c) Simulation HD

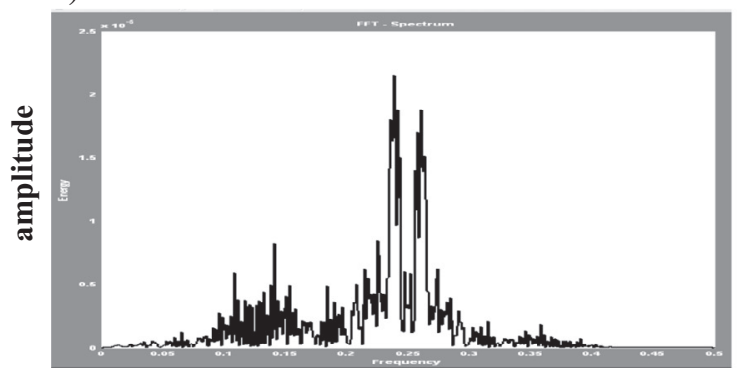

frequency $[\mathrm{kHz}]$ b) Simulation SB-D_p

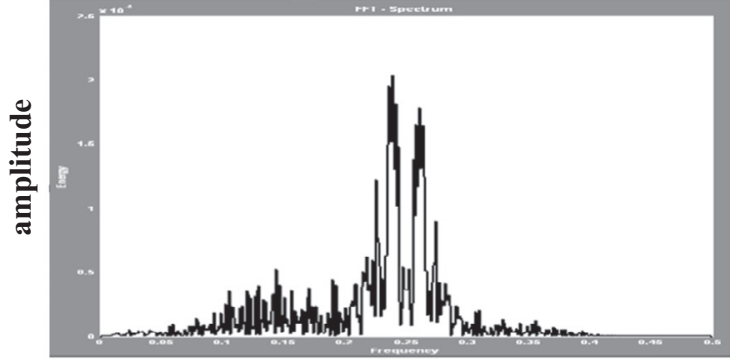

frequency $[\mathrm{kHz}]$

d) Simulation HD_p

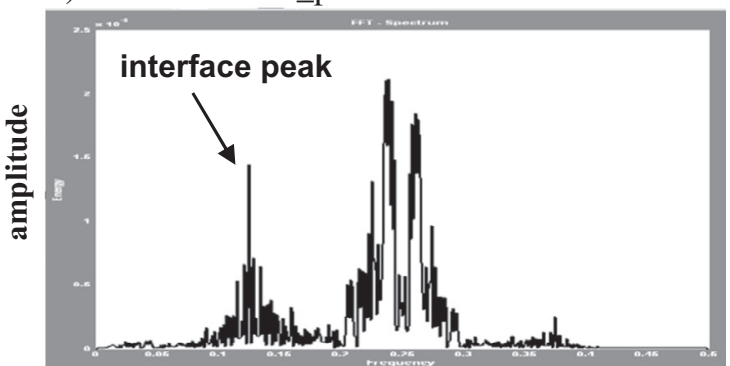

frequency $[\mathrm{kHz}]$

Fig. 16. Frequency spectrums for the specific detail - d2 of the IE signals for the simulated repair systems.

a) Simulation SB-D

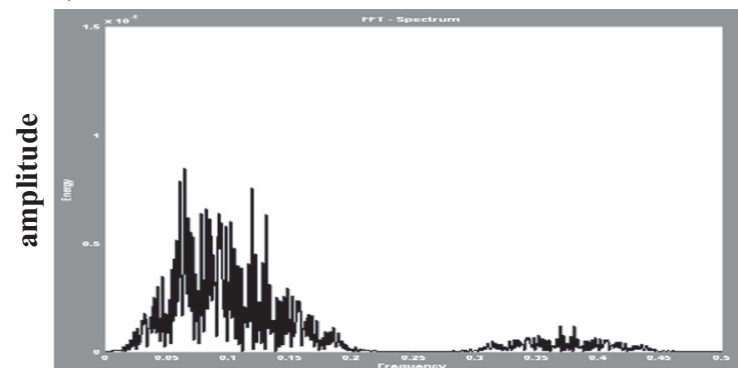

frequency $[\mathrm{kHz}]$

c) Simulation HD

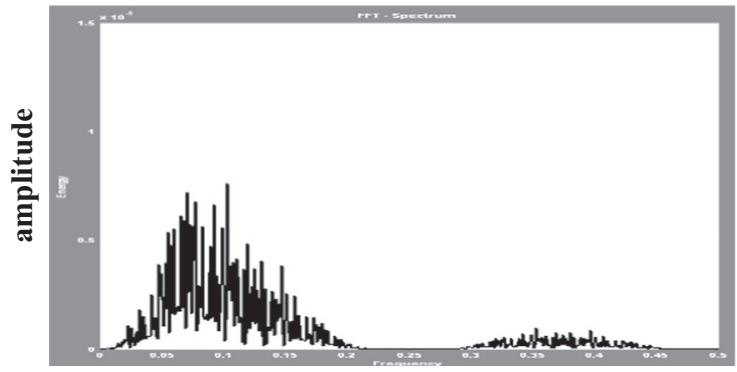

frequency $[\mathrm{kHz}]$ b) Simulation SB-D_p

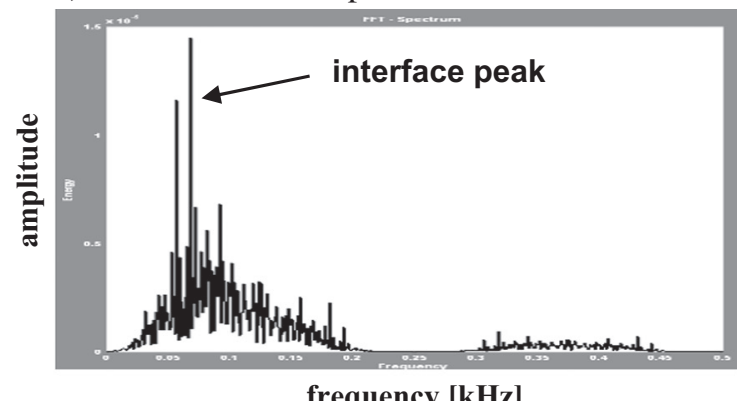

d) Simulation HD_p

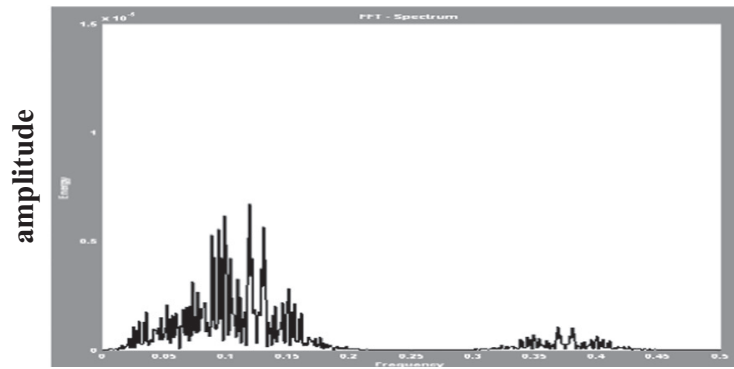

frequency $[\mathrm{kHz}]$

Fig. 17. Frequency spectrums for the specific detail - d3 of the IE signals for the simulated repair systems.

seemed to be Daubechies ( $\mathrm{db}$ ) wavelet. Fundamental for wavelet analysis is relation "scale - sine frequency" of wave phenomena. This relationship describes a pseudo-frequency $f_{a}$ Eq. (2):

$f_{a}=\frac{f_{c}}{a \cdot \Delta}$

where: $f_{c}$ - wavelet center frequency (frequency for dominant oscillation), $a$ - scale, $\Delta$ - sampling period in seconds.
According to this formula, the pseudo-frequencies may be calculated for both every scale level in CWT and every detail in DWT (see Table 6).

\subsection{CWT of experimental repair systems}

The CWT coefficient distribution diagrams obtained for real repaired systems are complex (Fig. 15). However, by comparison it is obvious that they depend, in some extend, on concrete 

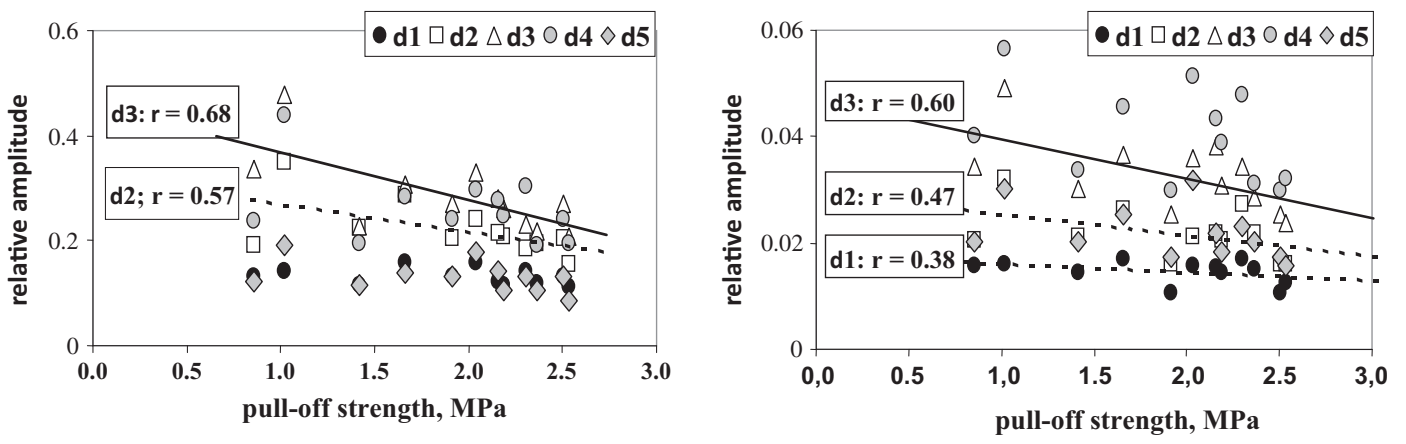

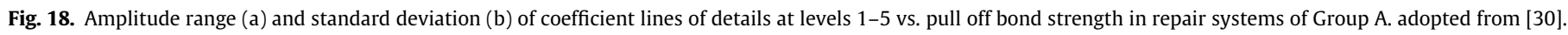

a)

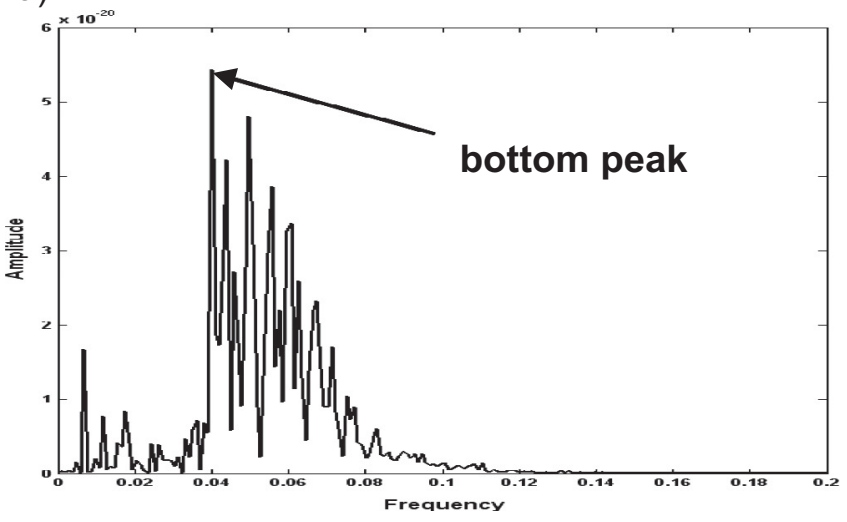

b)

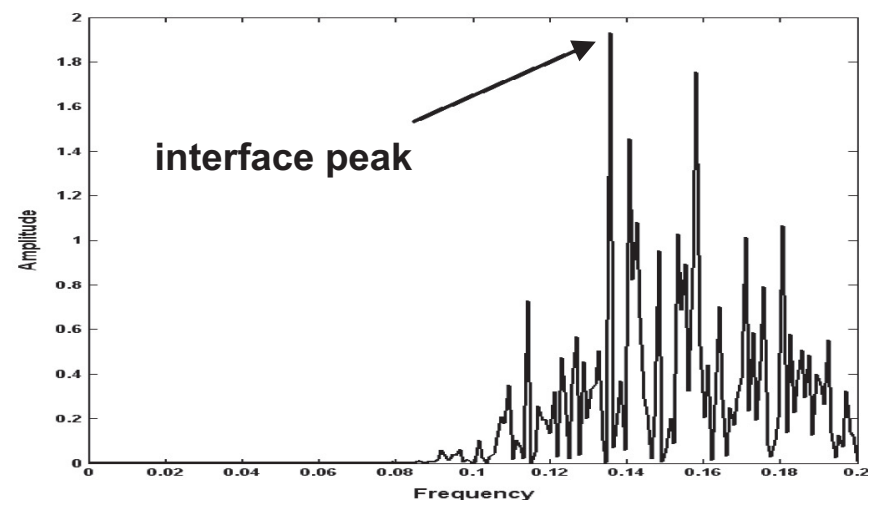

Fig. 19. Fast Fourier Transform (FFT) of the whole signal (a) de-noised one after separation of D2 partition (b).

substrate and bond interface quality. It is observed at both low frequency (high scale) and high frequency (low scale) regions.

\subsection{DWT of FE repair systems}

The DWT wavelet analysis was afterwards performed on FE simulated systems. The analysis of DWT results using db2 (Haar) wavelet presents the influence of air voids on stress wave propagation in repaired systems. This is not clearly visible by observation of DWT details but it is abviuos after the FFT (Fast Fourier Transform) analysis performed on each detail (Figs. 16 and 17). For the system HD_p (Fig. 16d) with high surface profile amplitude and air voids at the interface, a large amplitude peak at frequency that corresponds to the reflection from the interface is observed in $\mathrm{d} 2$. For the other systems the peak in these frequencies is present in d3: once again when there are air voids simulated (SB-D_p) its amplitude is the highest (Fig. 17b).

\subsection{DWT of experimental repair systems}

Analytical determination of scale and detail level for specific ranges of the frequency spectra (see Table 6) showed that the characteristic frequency ranges for interface echo are located at level d3-d2 and d4 for bottom [30]. Results of the DWT transform details d1-d5 were statistically analyzed using standard procedure of MATLAB by mean value (MEAN), mean absolute deviation (MAD), standard deviation (SD) and range of amplitude (RG). The relationship between statistical parameters of coefficient lines at different levels and pull-off strength shows that the information about quality of bond in repaired systems is localized at levels $\mathrm{d} 2, \mathrm{~d} 3$ - where the correlation factor is the highest (Fig. 18). The results of statistical analysis of DWT indicate that the most significant are relationships between the pull-off strength and the range and standard deviation of medium frequency detail d3 $(r \geqslant 0.60): r$ value $\leqslant 0.5$ for other details means weaker relation and lower significance. The mean value and absolute mean deviation versus the pull-off strength are not statistically significant. These results indicates that the most suitable parameter for characterization of bond quality in repaired system is a medium range of frequency. The basic tendency is that parameters describing deviation of detail amplitude increase as a pull-off strength increase.

Another advantage of wavelet analysis is de-noising and separation from the signal the part that is responsible for frequencies of interface area - in the analyzed case d2 (Fig. 19). On the FFT of the whole signal there is only visible a bottom peak on the frequency 0,04 (after recalculating - $20.48 \mathrm{kHz}$ ). After de-noising the signal in order to separate the partition of D2 in FFT amplitude, in frequency spectrum a peak on the frequency $0136(69,63 \mathrm{kHz})$ that corresponds to reflection from an interface appears.

\section{Conclusions}

On the basis of the results obtained for repair systems tested with impact-echo, the following main conclusions can be drawn:

- the relationships between pull-off strength and amplitudes of bottom and interface frequency peak are not statistically significant; this implies that an amplitude of frequency peaks is not proper measure of bond quality in repair systems;

- concrete substrate roughness and microcracking influence on stress wave propagation and increase the noise level in the IE frequency spectrum; 
- the FE simulation results for repaired system with different interface quality confirmed that developed model is useful for simulation of stress wave propagation trough repaired systems evaluated with impact-echo method. Due to the variety of parameters characterizing possible tested objects, experience is required to interpret impact-echo test results. The developed FE models of repair systems can be treated as a "ideal" reference repair systems.

- the results of wavelet analysis of IE signal indicate that this approach is promising for estimation of bond strength in repair systems.

The results presented here have been already introduced in development of a mobile, integrated diagnostic scanner equipment for non-destructive testing of concrete elements using three complementary methods - Ultrasonic - Impact-Echo - GeoRadar "UIRscanner" [31].

\section{Acknowledgments}

The paper was elaborated in the framework of the research project granted by The National Centre for Research and Development - grant number N R04 002410 (2010-2014). The part of the results of the research project supported by the Government of Poland (Ministry of Science and High Education) and the Regional Government of Wallonia, Belgium (Wallonia Brussels International) through Scientific Cooperation Program were used during preparation.

\section{References}

[1] L. Czarnecki, B. Chmielewska, Factors affecting the adhesion in building joints, Cement Wapno Beton 2 (2005) 74-85.

[2] J. Silfwerbrand, H. Beushausen, Bonded concrete overlays - bond strength issues, in: H. Beushausen, F. Dehn, M.G. Alexander (Eds.), Proceedings ICCRRR 2005 International Conference on Concrete Repair, Rehabilitation and Retrofitting, Cape Town, South Africa, Taylor \& Francis Group, London, 2006, pp. 19-21.

[3] A. Halicka, Ł. Jabłoński, Shear failure mechanism of composite concrete Tshaped beams, PI Civ. Eng.-Str 169 (1) (2016) 67-75, http://dx.doi.org/ 10.1680/stub.14.00127.

[4] B. Bissonnette, L. Courard, A. Garbacz, Concrete Surface Engineering. Modern Concrete Technology 18, CRC Press, 2015. 272p. (ISBN-13: 978-1498704885).

[5] L. Courard, Parametric study for the creation of the interface between concrete and repair products, Mater. Struct. 33 (1) (2000) 65-72, http://dx.doi.org/ 10.1007/BF02481698.

[6] EN 1504. Products and systems for the protection and repair of concrete structures - Definitions - Requirements - Quality control and evaluation of conformity, CEN (Brussels).

[7] EN 1542. Products and systems for the protection and repair of concrete structures. Test methods - measurement of bond strength by pull-off. CEN (Brussels).

[8] Concrete Repair Manual, ACI International, Farmington Hills, MI, USA, 2003.

[9] ACI 562-16: Code Requirements for Assessment, Repair, and Rehabilitation of Existing Concrete Structures and Commentary.

[10] J. Hola, K. Schabowicz, State-of-the-art non-destructive methods for diagnostic testing of building structures anticipated development trends, Arch. Civ. Mech. Eng. 10 (3) (2010) 5-18, http://dx.doi.org/10.1016/S1644-9665(12)60133-2.

[11] M.J. Sansalone, W.B. Street, Impact-Echo. Nondestructive Evaluation of Concrete and Masonry, Bulbrier Press, Ithaca NY, 1997.
[12] J.M. Lin, M. Sansalone, R. Poston, Impact-echo studies of interfacial bond quality in concrete: part II - effects of bond tensile strength, ACI Mater. J. 93 (4) (1996) 318-326, http://dx.doi.org/10.14359/9817.

[13] A. Garbacz, L. Courard, B. Bissonnette, A surface engineering approach applicable to concrete repair engineering, Bull. Pol. Acad. Sci. 61 (1) (2013) 73-84, http://dx.doi.org/10.2478/bpasts-2013-0006.

[14] L. Courard, F. Michel, D. Schwall, A. Van der Wielen, T. Piotrowski, A. Garbacz, F. Perez, B. Bissonette, Surfology: concrete surface evaluation prior to repair, in: AA. Mammoli, CA Brebbia (Eds.), Materials Characterisation IV, Computational Methods and Experiments, WIT Press, 2009, pp. 407-416, http://dx.doi.org/10.2495/MC090381.

[15] B. Bissonnette, L. Courard, A. Vaysburd, N. Bélair, Concrete removal techniques: influence on residual cracking and bond strength, Concr. Int. 28 (12) (2006) 49-55.

[16] L. Courard, J.-F. Lenaers, F. Michel, A. Garbacz, Saturation level of the superficial zone of concrete and adhesion of repair systems, Constr. Build.

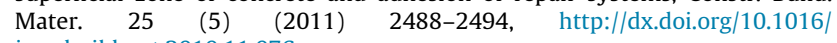
j.conbuildmat.2010.11.076.

[17] A. Garbacz, M. Górka, L. Courard, On the effect of concrete surface treatment on adhesion in repair systems, Mag. Concr. Res. 57 (2005) 49-60, http://dx.doi. org/10.1680/macr.2005.57.1.49.

[18] J. Hoła, L. Sadowski, J. Reiner, S. Stach, Usefulness of 3D surface roughness parameters for nondestructive evaluation of pull-off adhesion of concrete layers, Constr. Build. Mater. 84 (1) (2015) 111-120, http://dx.doi.org/10.1016/ j.conbuildmat.2015.03.014.

[19] L. Courard, T. Piotrowski, A. Garbacz, Near-to-surface properties affecting bond strength in concrete repair, Cem. Concr. Comp. 46 (2014) 73-80, http://dx.doi. org/10.1016/j.cemconcomp.2013.11.005.

[20] R. Muldoon, A. Chalker, M.C. Forde, M. Ohtsu, F. Kunisue, Identifying voids in plastic ducts in post-tensioning prestressed concrete members by resonant frequency of impact-echo, SIBIE and tomography, Constr. Build. Mater. 21 (3) (2007) 527-537, http://dx.doi.org/10.1016/j.conbuildmat.2006.04.009.

[21] C. Hsiaoa, C.C. Cheng, T. Liou, Y. Juang, Detecting flaws in concrete blocks using the impact-echo method, NDT\&E Int. 41 (2) (2008) 98-107, http://dx.doi.org/ 10.1016/j.ndteint.2007.08.008.

[22] J. Hola, L. Sadowski, K. Schabowicz, Nondestructive identification of delaminations in concrete floor toppings with acoustic methods, Automat. Constr. $20 \quad$ (7) (2011) 799-807, http://dx.doi.org/10.1016/j. autcon.2011.02.002.

[23] A. Garbacz, Stress wave propagation troughout an interface: PCC compositesconcrete substrate in repair system, Arch. Civ. Eng. Environ. 3 (3) (2010) 3544.

[24] P. Santos, E. Júlio, J. Santos, Towards the development of an in situ nondestructive method to control the quality of concrete-to-concrete interfaces, Eng. Struct. 32 (1) (2011) 207-217, http://dx.doi.org/10.1016/j. engstruct.2009.09.007.

[25] L. Kwaśniewski, A. Garbacz, Computer simulation of stress wave propagation in repair systems, in: L. Czarnecki, A. Garbacz (Eds.), Adhesion in Interfaces of Building Materials: a Multi-scale Approach, Advances in Materials Science and Restoration AMSR No. 2, Aedificatio Publishers, 2007, pp. 207-216.

[26] A.V. Ovanesova, L.E. Suarez, Applications of wavelet transforms to damage detection in frame structures, Eng. Struct. 26 (1) (2004) 39-49, http://dx.doi. org/10.1016/j.engstruct.2003.08.009.

[27] M. Rucka, K. Wilde, Crack identification using wavelets on experimental static deflection profiles, Eng. Struct. 28 (2) (2006) 279-288, http://dx.doi.org/ 10.1016/j.engstruct.2005.07.009.

[28] Y. Po-Liang, L. Pei-Ling, Application of the wavelet transform and the enhanced Fourier spectrum in the impact echo test, NDT\&E Int. 41 (5) (2008) 382-394, http://dx.doi.org/10.1016/j.ndteint.2008.01.002.

[29] MatLab 6.13., “Wavelet toolbox. User's guide”, The MathWorks (2006).

[30] A. Garbacz, T. Piotrowski, L. Courard, Analysis of stress wave propagation in repair systems using wavelet approach, in: J. Marchand, B. Bissonnette, R. Gagne, M. Jolin, F. Paradis (Eds.), 2nd International RILEM Symposium on Advances in Concrete through Science and Engineering, RILEM PRO 51, RILEM Publications SARL, 2006, http://dx.doi.org/10.1617/2351580028.092.

[31] A. Garbacz, T. Piotrowski, K. Zalegowski, G. Adamczewski, UIR-scanner potential to defekt detection in cocnrete, in: R. Wang, Z.H. Yang (Ed.), Progress in Polymers in Concrete, Advanced Materials Research 687 (2013) 359-365. doi:10.4028/www.scientific.net/AMR.687.359. 